ORIGINAL RESEARCH

\title{
Management of Supratherapeutic International Normalized Ratio without Bleeding after Warfarin Use: An Evaluation of Vitamin K Administration (SUPRA-WAR-K Study)
}

Claire Tai, Hilary Wu, Cindy San, and Doson Chua

\begin{abstract}
Background: For patients with supratherapeutic international normalized ratio (INR) and no evidence of bleeding, the 2012 guidelines of the American College of Chest Physicians discourage administration of vitamin $\mathrm{K}$. At the study hospital, it was observed that vitamin $\mathrm{K}$ was frequently prescribed for patients with INR of 4.5 or higher and no bleeding.

Objectives: To compare efficacy and safety outcomes between holding warfarin alone and holding warfarin with administration of vitamin $\mathrm{K}$ and to compare these outcomes among various doses and routes of vitamin $\mathrm{K}$ administration in non-critical care inpatients experiencing supratherapeutic INR without evidence of bleeding.

Methods: This single-centre retrospective chart review involved noncritical care inpatients with supratherapeutic INR (4.5-8.9) without evidence of bleeding. The primary outcomes were the change in INR 1 day after implementation of supratherapeutic INR management and the time to reach INR less than 3.0. The secondary outcomes were length of stay, frequency of warfarin resistance, incidence and duration of bridging anticoagulation, incidence of thromboembolism and major bleeding, and death.

Results: Regardless of vitamin K dose, the administration of vitamin K combined with holding warfarin, relative to holding warfarin alone, was associated with a greater INR decrease 1 day after the intervention (mean \pm standard deviation $-3.2 \pm 1.9$ versus $-0.9 \pm 1.0, p<0.001$ ) and a shorter time to reach INR below $3.0(1.9 \pm 1.0$ days versus $2.6 \pm 1.4$ days, $p=0.003)$. No statistically significant differences in any other outcomes were observed.

Conclusions: In hospitalized non-critical care patients with INR between 4.5 and 8.9 without evidence of bleeding, the combination of holding warfarin and administering vitamin $\mathrm{K}$ was associated with greater and faster decreases in INR than holding warfarin alone. No significant differences were found in clinically important outcomes. The practice of administering vitamin $\mathrm{K}$ in this population warrants further study and re-evaluation.
\end{abstract}

\section{RÉSUMÉ}

Contexte : Dans ses lignes directrices de 2012, l'American College of Chest Physicians déconseille l'administration de vitamine $\mathrm{K}$ aux patients ayant des résultats de rapport international normalisé (RIN) suprathérapeutiques et ne présentant aucun saignement. À l'hôpital des auteurs, on a remarqué que l'on prescrivait fréquemment de la vitamine $\mathrm{K}$ aux patients répondant aux critères ci-dessus.

Objectifs : Comparer l'efficacité et l'innocuité entre un simple arrêt de la warfarine et l'arrêt de la warfarine combiné à l'administration de vitamine $\mathrm{K}$, puis comparer ces résultats thérapeutiques selon différentes doses et voies d'administration de la vitamine $\mathrm{K}$ chez des patients hospitalisés qui ne sont pas en phase critique, qui ont un RIN suprathérapeutique et qui ne présentent aucun saignement.

Méthodes : La présente étude menée dans un seul centre comportait une analyse des dossiers médicaux de patients hospitalisés n'étant pas en phase critique, ayant un RIN suprathérapeutique (4.5-8.9) et ne présentant aucun saignement. Les principaux paramètres d'évaluation étaient le changement du RIN un jour après la mise en œuvre de mesures pour corriger un RIN suprathérapeutique et le temps nécessaire pour atteindre un RIN de moins de 3,0. Les paramètres d'évaluation secondaires étaient la durée du séjour, la fréquence des cas de résistance à la warfarine, le nombre et la durée des relais anticoagulants, l'incidence des cas de thromboembolie et de saignement important et les cas de décès.

Résultats : L'administration de vitamine K, peu importe la dose, combinée à l'arrêt de la warfarine comparativement au simple arrêt de la warfarine était associée à une réduction plus importante du RIN un jour après l'intervention (moyenne \pm écart-type $-3.2 \pm 1,9$ contre $-0,9 \pm 1,0$, $p<0,001)$ et à un plus court délai pour atteindre un RIN de moins de $3,0(1,9 \pm 1,0$ jour contre 2,6 $\pm 1,4$ jours, $p=0.003)$. Aucune différence statistiquement significative n'a été observée pour le reste des paramètres d'évaluation.

Conclusions : Chez les patients hospitalisés n'étant pas en phase critique, ayant un RIN entre 4,5 et 8,9 et ne présentant aucun saignement, l'arrêt de la warfarine combiné à l'administration de vitamine $\mathrm{K}$ a été associé à 
Keywords: anticoagulation, international normalized ratio, phytonadione, vitamin $\mathrm{K}$, warfarin

Can J Hosp Pharm. 2017;70(3):207-14 une réduction plus rapide et plus importante du RIN que le simple arrêt de la warfarine. On n'a observé aucune différence significative en ce qui touche aux résultats thérapeutiques cliniquement importants. L'administration de vitamine $\mathrm{K}$ pour cette population est une pratique qui nécessite de plus amples études et doit être évaluée à nouveau.

Mots clés : anticoagulothérapie, rapport international normalisé, phytonadione, vitamine $\mathrm{K}$, warfarine

\section{INTRODUCTION}

$\mathrm{W}^{\mathrm{N}}$ arfarin is a widely used anticoagulant that must be routinely monitored by measurement of international normalized ratio (INR) to prevent hemorrhage and thrombosis, secondary to over- and under-anticoagulation, respectively. ${ }^{1,2}$ In particular, at INR values above 4.5, the risk of hemorrhage rises significantly, and it is important in such cases to employ appropriate measures to return the INR to therapeutic range. ${ }^{3,4}$

At the authors' tertiary care hospital, it has been observed that patients with INR of 4.5 or higher and no evidence of bleeding commonly receive vitamin $\mathrm{K}$ as an INR reversal agent, by various routes and at various doses, in addition to withholding of warfarin. The 2012 American College of Chest Physicians (ACCP) guidelines discourage administration of vitamin $\mathrm{K}$ when INR is between 4.5 and 10.0 without evidence of bleeding, citing the lack of evidence of benefit for patient-important outcomes, such as major bleeding, thromboembolism, and all-cause mortality. ${ }^{5}$ Instead, the ACCP recommends simply holding the warfarin. ${ }^{5}$ This recommendation contrasts with previous editions of the ACCP guidelines, ${ }^{6}$ which gave the option of oral vitamin $\mathrm{K}$ at doses of up to $5 \mathrm{mg}$ for INR 5.0-9.0, particularly for patients at high risk of bleeding. The evidence for this earlier recommendation $^{6}$ was presented as individual study results, whereas the current (2012) guideline recommendations ${ }^{5}$ are based upon a pooled analysis of 4 studies, including 2 studies that had not been examined previously. As a result of this additional evidence and re-analysis of data, the utility of vitamin $\mathrm{K}$ for patients who have supratherapeutic INR without evidence of bleeding has been called into question.

In addition, the applicability of the ACCP guidelines for acute care patients is not well known, given that the guidelines reflect primarily the findings of outpatient studies. ${ }^{5}$ The evidence for vitamin $\mathrm{K}$ in hospitalized patients is limited to a small number of studies with populations that combined critical care and non-critical care patients or inpatients and outpatients. ${ }^{78}$ To our knowledge, there have been no published studies examining the efficacy and safety of vitamin K solely in hospitalized non-critical care patients, nor have there been subgroup analyses focusing on this population in existing studies. Compared with outpatients, acutely ill inpatients are at an increased risk of coagulation abnormalities. ${ }^{9}$ For example, in one review, the rate of venous thromboembolism was 135 times greater in hospitalized patients than in community residents. ${ }^{10}$ Other potential consequences of suboptimal anticoagulation management in hospitalized patients include warfarin resistance, the need for bridging anticoagulation, adverse outcomes such as bleeding and thromboembolism, and increased length of stay. ${ }^{11,12}$

The overall aim of this study was to determine the optimal management of supratherapeutic INR in hospitalized non-critical care patients. Specifically, the primary objective was to compare efficacy and safety outcomes between hospitalized non-critical care patients whose warfarin was simply held and those whose warfarin was held with addition of vitamin $\mathrm{K}$ therapy. The secondary objective was to compare efficacy and safety for various doses and routes of vitamin $\mathrm{K}$ administration.

\section{METHODS}

\section{Design}

A single-centre retrospective chart review was performed at Providence Health Care in Vancouver, British Columbia. The study was approved by the University of British ColumbiaProvidence Health Care Research Ethics Board, and the need for informed consent was waived.

\section{Population}

Patients were screened for eligibility (through the hospital laboratory database and through patient charts), and those who met the following criteria were included: age 18 years or older; admitted to the hospital's Internal Medicine service between January 1, 2010, and December 31, 2015; received warfarin therapy before and/or during the admission; INR between 4.5 and 8.9 at any point during the admission (with the study centre's upper limit of detection being 9.0); warfarin dose held with or without administration of vitamin $\mathrm{K}$ for management of supratherapeutic INR; no evidence of bleeding or thromboembolic events before the intervention for management of supratherapeutic INR; and target INR of 2.0-3.0. Patients were excluded from the 
study for one or more of the following reasons: received more than one dose of vitamin K during the admission; received fresh frozen plasma, prothrombin complex concentrate, or recombinant factor VIIa; absence of INR information after the intervention for management of supratherapeutic INR; underwent surgery during the admission; had severe liver disease, defined as documented cirrhosis and/or aminotransferases (aspartate aminotransferase or alanine aminotransferase) at least 5 times the upper limit of normal; had a known bleeding disorder; and/or were transferred to a critical care unit.

\section{Outcomes}

The primary outcomes were the change in INR 1 day after the intervention for management of supratherapeutic INR and the time required for INR to return to 3.0 or below. Management refers to holding warfarin doses alone or holding warfarin and administering vitamin K. Secondary outcomes were the length of stay in hospital after the intervention for management of supratherapeutic INR, frequency of development of warfarin resistance, the incidence and duration of bridging anticoagulation back to warfarin, the incidence of thromboembolic and major bleeding events, and the mortality rate.

Warfarin resistance was defined as the inability to reach INR of 2.0 or higher after administration of at least 4 warfarin doses, the average of which was more than or equal to the baseline warfarin dose. Thromboembolic events were defined as ischemic stroke, transient ischemic attack, systemic embolism, or cardiac valve thrombosis objectively confirmed with imaging. These definitions were based upon clinical knowledge and experience. A major bleeding event was defined as fatal bleeding; a decrease in hemoglobin greater than $20 \mathrm{~g} / \mathrm{L}$; bleeding that was intracranial, intraspinal, intraocular, retroperitoneal, intra-articular, pericardial, or intramuscular with compartment syndrome; and/or bleeding that required operation or blood transfusion as per the International Society on Thrombosis and Haemostasis. ${ }^{13}$

\section{Statistical Analysis}

A convenience sample of patients who met the inclusion criteria was obtained for the period January 1, 2010, to December 31, 2015.

Statistical analyses were performed using SPSS Statistics, version 23 (IBM, Armonk, New York) and Microsoft Excel 2013 (Microsoft Corporation, Redmond, Washington). Descriptive statistics were used to tabulate the demographic variables and primary outcomes.

Analyses of the baseline characteristics and the primary and secondary outcomes comparing patients whose warfarin was held with those who also received vitamin $\mathrm{K}$ were completed using the Student $t$ test for continuous variables and the Fisher exact test for categorical variables. For the patients who received vitamin $\mathrm{K}$, primary and secondary outcomes were compared among different doses and various routes of administration. The vitamin $\mathrm{K}$ doses were divided into 5 groups: $0 \mathrm{mg}, 0.1-2.4 \mathrm{mg}, 2.5-4.9 \mathrm{mg}$, 5.0-7.4 mg, and 7.5-10 mg. The routes of administration were grouped into 3 categories: oral, intravenous (IV), and subcutaneous. Outcome comparisons were performed using analysis of variance (ANOVA) for continuous variables and the Fisher exact test with Freeman-Halton extension for categorical variables. The Tukey test was used to perform multiple comparisons between groups when ANOVA results were found to be statistically significant.

All tests were 2 -tailed, and $p$ values less than 0.05 were considered statistically significant for all tests.

\section{RESULTS}

A total of 496 inpatient records were reviewed, and 146 patients met the inclusion criteria (Figure 1). Demographic and clinical characteristics were similar among those who received vitamin $\mathrm{K}$ and those who only had warfarin held, with the exception of baseline supratherapeutic INR, which was higher among those who received vitamin $\mathrm{K}(5.7$ versus $5.1, p<0.001)$

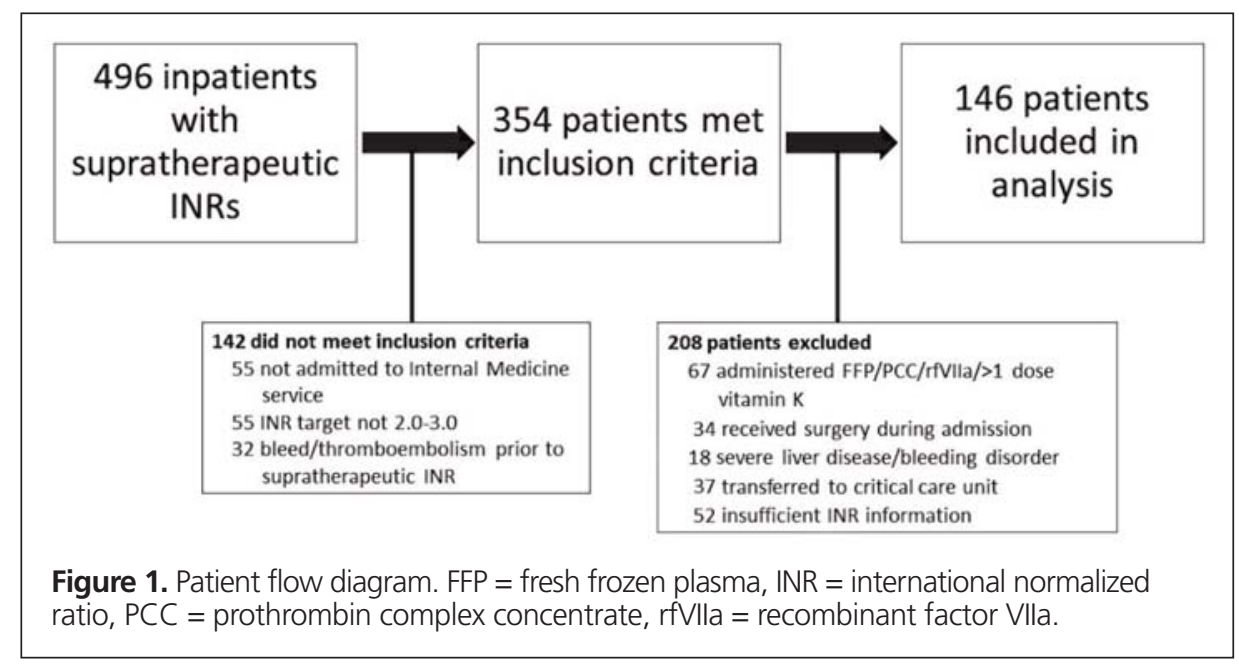


(Table 1$)$. A total of 87 patients $(60 \%)$ had warfarin held without addition of vitamin $\mathrm{K}$. Of the 59 patients (40\%) who also received vitamin $\mathrm{K}$, the prescribed doses and routes varied (Table 2). Vitamin $\mathrm{K}$ was prescribed via the oral, IV, and subcutaneous routes at rates of 78\% (46/59), 15\% (9/59), and 7\% (4/59), respectively, and doses ranged from $1 \mathrm{mg}$ to $10 \mathrm{mg}$. It was noted that $65 \%(17 / 26)$ of patients with supratherapeutic INR of 6.0 or higher received vitamin $K$, as compared with $35 \%$ (42/120) of patients with supratherapeutic INR of 5.9 or below.

Patients who received vitamin $\mathrm{K}$ had a significantly greater change in INR 1 day after implementation of management measures than those who only had warfarin held $(-3.2 \pm 1.9$ versus $-0.9 \pm 1.0, p<0.001$ ) (Table 3, Figure 2). In addition, vitamin $\mathrm{K}$ administration was associated with a statistically significant decrease in time to reach INR below 3.0, relative to holding warfarin alone $(1.9 \pm 1.0$ days versus $2.6 \pm 1.4$ days, $p=0.003$ ) (Table 3).

INR outcomes among the various doses and routes of vitamin $\mathrm{K}$ were largely similar. The only statistically significant difference was in the change in INR 1 day after implementation of management measures in the dose comparison (Table 4). The Tukey test revealed that this difference was a result of comparing the 1-day change in INR for the group that did not receive vitamin $\mathrm{K}$ (dose $0 \mathrm{mg}$ ) with any of the other vitamin $\mathrm{K}$ dose groups.

No statistically significant differences were found in the secondary clinical outcomes in any of the analyses. Two bleeding events occurred: a drop in hemoglobin of more than $20 \mathrm{~g} / \mathrm{L}$ in a patient who received $10 \mathrm{mg}$ vitamin K orally (INR 4.2 on day of bleed) and an event requiring blood transfusion in a patient who only had warfarin held (INR 1.8 on day of bleed). No

Table 1. Baseline Demographic and Clinical Characteristics

\begin{tabular}{|c|c|c|c|}
\hline \multirow[b]{2}{*}{ Characteristic } & \multicolumn{2}{|c|}{ Intervention; No. (\%) of Patients* } & \multirow[b]{2}{*}{$p$ Value } \\
\hline & $\begin{array}{l}\text { Warfarin Held } \\
\quad(n=87)\end{array}$ & $\begin{array}{l}\text { Warfarin Held }+ \\
\text { Vitamin K Given } \\
\quad(n=59)\end{array}$ & \\
\hline Age (years) (mean \pm SD) & $75.5 \pm 13.8$ & $77.4 \pm 13.5$ & 0.41 \\
\hline Sex, male & $48(55)$ & $35(59)$ & 0.73 \\
\hline \multicolumn{4}{|l|}{ Indication for warfarin } \\
\hline Atrial fibrillation & $75(86)$ & $47(80)$ & 0.36 \\
\hline Left ventricular thrombus & 1 (1) & $2(3)$ & 0.57 \\
\hline Recurrent VTE & $7 \quad(8)$ & $7(12)$ & 0.57 \\
\hline Aortic valve replacement & $2(2)$ & $2 \quad(3)$ & $>0.99$ \\
\hline Othert & $2(2)$ & $1 \quad(2)$ & \\
\hline Supratherapeutic INR (mean \pm SD) & $5.1 \pm 0.7$ & $5.7 \pm 1.0$ & $<0.001$ \\
\hline $\begin{array}{l}\text { Daily warfarin dose before supratherapeutic } \\
\text { INR }(\mathrm{mg})(\text { mean } \pm \text { SD) } \neq\end{array}$ & $4.2 \pm 2.4$ & $4.4 \pm 2.1$ & 0.56 \\
\hline \multicolumn{4}{|l|}{$\begin{array}{l}\text { Receiving } \geq 1 \text { medications that interact } \\
\text { with warfarin§ }\end{array}$} \\
\hline Medications that increase INR & $72(83)$ & $52(88)$ & 0.48 \\
\hline Medications that decrease INR & $2(2)$ & $4(7)$ & 0.22 \\
\hline \multicolumn{4}{|c|}{$\begin{array}{l}\text { INR = international normalized ratio, SD = standard deviation, VTE = venous thromboembolism. } \\
\text { *Except where indicated otherwise. } \\
\text { tIncludes Eisenmenger syndrome, renal artery thrombosis, and anteroseptal akinesis. } \\
\text { fMean daily dose was defined as the mean of the } 4 \text { doses before identification of supratherapeutic INR } \\
\text { or the home dose as listed on the admission note (if previous } 4 \text { doses were unknown). } \\
\text { §Interacting medications included all medications that could have potentially caused an increase or decrease } \\
\text { in the anticoagulant activity of warfarin. }\end{array}$} \\
\hline
\end{tabular}

Table 2. Prescribed Method of Management for Supratherapeutic INR

\begin{tabular}{|c|c|c|c|c|}
\hline \multirow[b]{2}{*}{ INR Level } & \multicolumn{4}{|c|}{ Method of Management; No. (\%) of Patients or Mean \pm SD } \\
\hline & $\begin{array}{l}\text { Warfarin Held* } \\
\quad(n=87)\end{array}$ & $\begin{array}{c}\text { Oral Vitamin } \mathrm{K} \dagger \\
(n=46)\end{array}$ & $\begin{array}{c}\text { IV Vitamin K† } \\
(n=9)\end{array}$ & $\begin{array}{c}\text { SC Vitamin } \mathrm{K} \dagger \\
(n=4)\end{array}$ \\
\hline $4.5-5.9(n=120)$ & $78(90)$ & $\begin{array}{c}33(72) \\
\text { Dose } 3.6 \pm 4.0 \mathrm{mg}\end{array}$ & $\begin{array}{c}6(67) \\
\text { Dose } 2.8 \pm 2.7 \mathrm{mg}\end{array}$ & $\begin{array}{c}3(75) \\
\text { Dose } 3.0 \pm 2.8 \mathrm{mg}\end{array}$ \\
\hline $6.0-7.4(n=20)$ & $7 \quad(8)$ & $\begin{array}{c}10(22) \\
\text { Dose } 2.3 \pm 0.4 \mathrm{mg} \\
\end{array}$ & $\begin{array}{c}2(22) \\
\text { Dose } 4.2 \pm 3.4 \mathrm{mg} \\
\end{array}$ & $\begin{array}{c}1(25) \\
\text { Dose } 2.0 \mathrm{mg} \\
\end{array}$ \\
\hline $7.5-8.9(n=6)$ & $2 \quad(2)$ & $\begin{array}{c}3(7) \\
\text { Dose } 10.0 \pm 0 \mathrm{mg}\end{array}$ & $\begin{array}{c}1(11) \\
\text { Dose } 3.3 \pm 2.1 \mathrm{mg}\end{array}$ & $\begin{array}{l}0(0) \\
\text { NA }\end{array}$ \\
\hline
\end{tabular}


Table 3. Safety and Efficacy of Interventions for Management of Supratherapeutic INR

\begin{tabular}{|c|c|c|c|}
\hline \multirow[b]{2}{*}{ Outcome Measure } & \multicolumn{2}{|c|}{$\begin{array}{c}\text { Patient Group; } \\
\text { Mean } \pm \text { SD or No. (\%) of Patients }\end{array}$} & \multirow[b]{2}{*}{$p$ Value } \\
\hline & $\begin{array}{l}\text { Warfarin Held* } \\
\quad(n=87)\end{array}$ & $\begin{array}{c}\text { Received } \\
\text { Vitamin K† } \\
(n=59)\end{array}$ & \\
\hline Change in INR 1 day after intervention & $-0.9 \pm 1.0$ & $-3.2 \pm 1.9$ & $<0.001$ \\
\hline Time to INR $<3.0$ (days) & $2.6 \pm 1.4$ & $1.9 \pm 1.0$ & 0.003 \\
\hline $\begin{array}{l}\text { Length of stay after intervention for } \\
\text { supratherapeutic INR (days) }\end{array}$ & $12.1 \pm 12.4$ & $12.9 \pm 11.2$ & 0.71 \\
\hline \multicolumn{4}{|l|}{ Bridging anticoagulation } \\
\hline No. of patients & $6(7)$ & $7(12)$ & 0.38 \\
\hline Duration (days) & $2.0 \pm 3.7$ & $1.7 \pm 2.9$ & 0.75 \\
\hline Thromboembolism & $0(0)$ & $0(0)$ & NA \\
\hline Major bleeding & $1(1)$ & $1(2)$ & $>0.99$ \\
\hline Death & $8(9)$ & $6(10)$ & $>0.99$ \\
\hline
\end{tabular}

INR = international normalized ratio, NA = not applicable, SD = standard deviation.

*No medications were added to the patient's regimen.

tFor all patients who received vitamin K, warfarin was held.

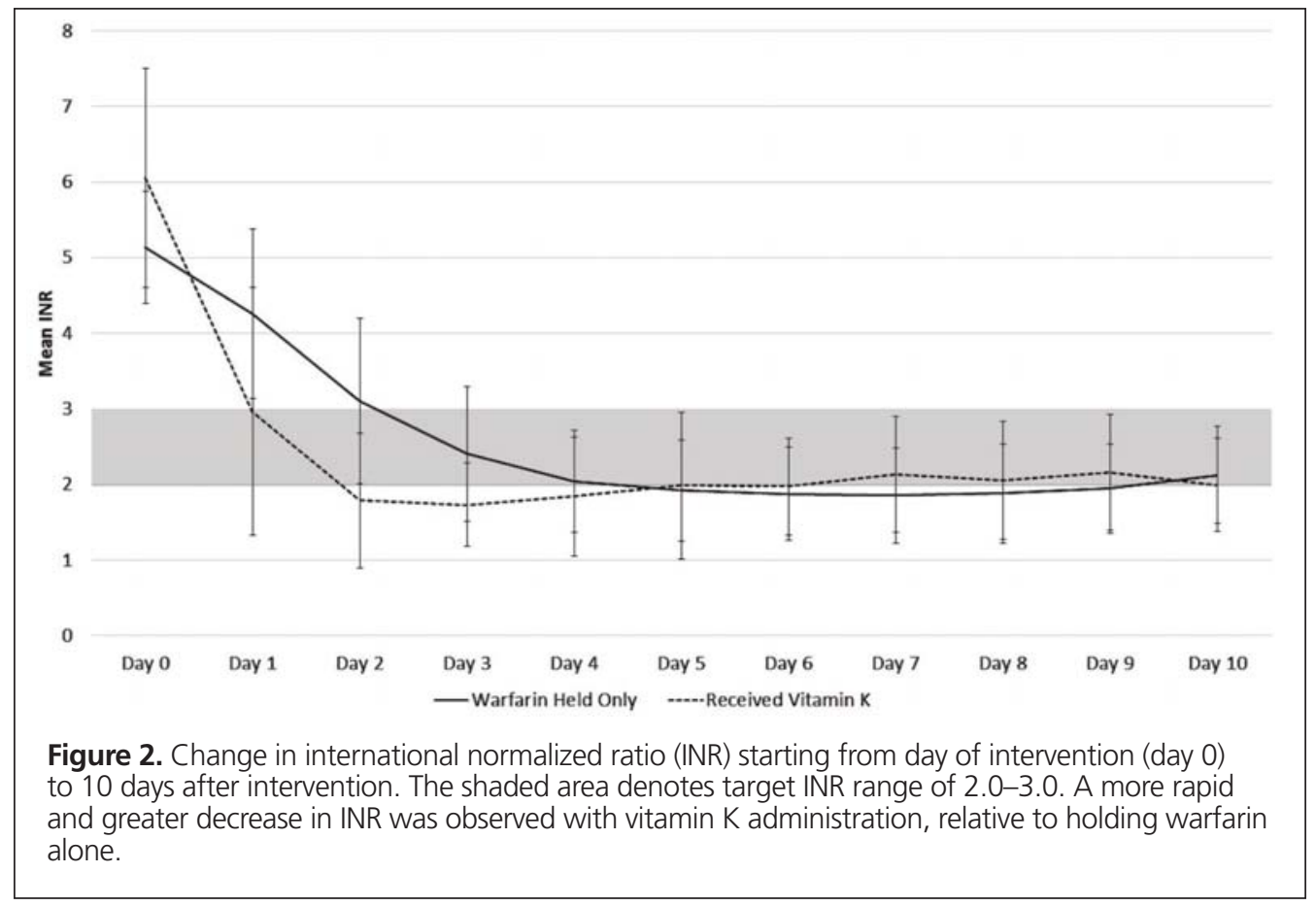

thromboembolic events occurred. Warfarin resistance was observed in 2 patients: one patient had received vitamin $\mathrm{K} 5 \mathrm{mg}$ orally, and the other had received vitamin $\mathrm{K} 5 \mathrm{mg}$ subcutaneously. A total of 14 deaths occurred during the hospital stay, none of which were due to thromboembolism or bleeding.

\section{DISCUSSION}

To the authors' knowledge, this is the first study to examine the use of vitamin $\mathrm{K}$ specifically in hospitalized patients in the non-critical care setting. Despite ACCP guidelines recommending against use of vitamin $\mathrm{K}$ for patients with INR between
4.5 and 10.0 and no evidence of bleeding, the prescribing of vitamin $\mathrm{K}$ was a common practice at the study institution, particularly for patients with INR of 6.0 or above. In addition, the prescribed doses and routes of administration for vitamin $\mathrm{K}$ varied, likely because of the lack of dosing protocols and guidelines. It was unclear how prescribers decided upon which route or dose to order. In these patients, vitamin $\mathrm{K}$ administration shortened the length of time required to return to INR of 3.0 or below, thereby theoretically returning patients to a state with a lower risk of bleeding more quickly than holding warfarin alone. However, these results suggest that, although administration of vitamin $\mathrm{K}$ can lead to significant decreases in INR more quickly 


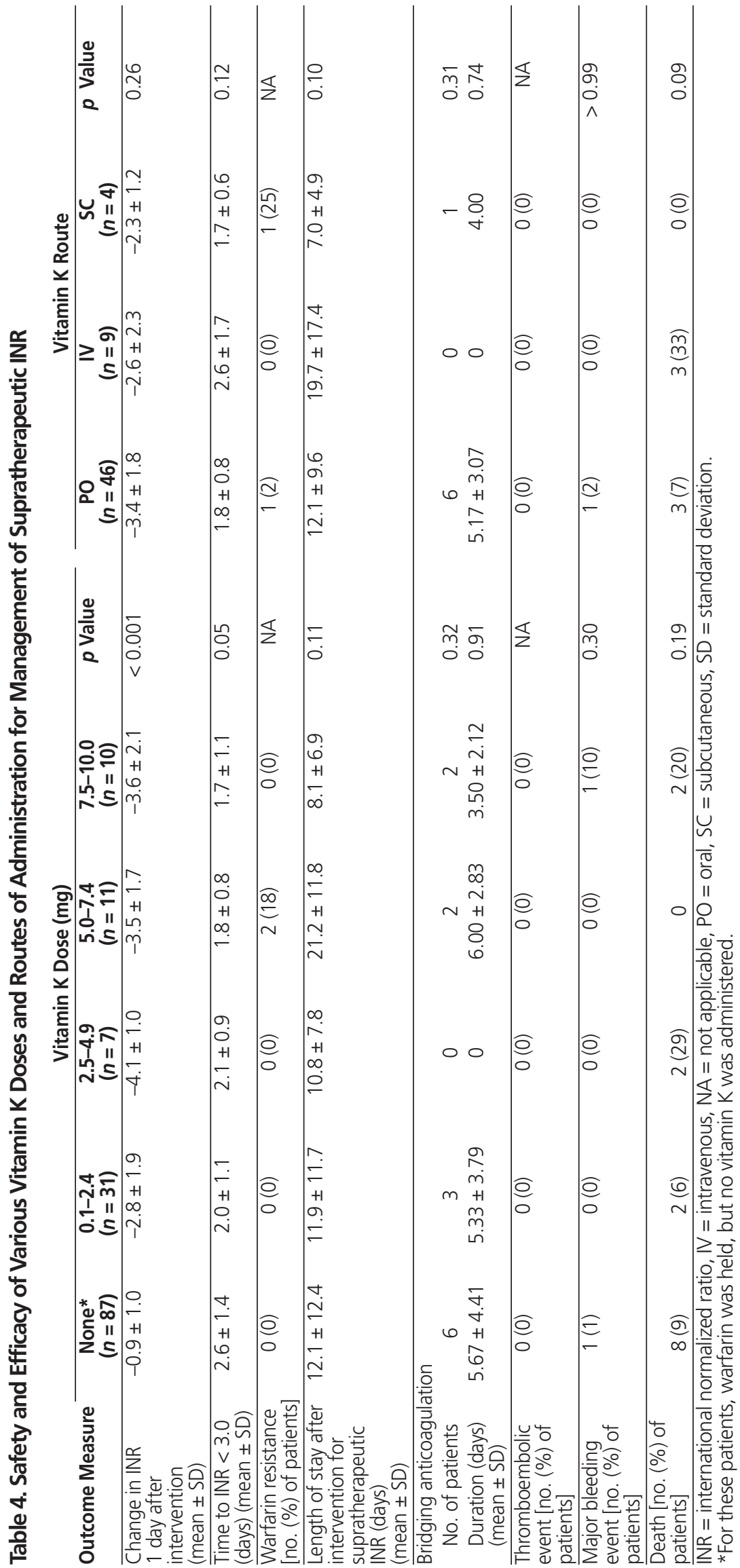


than holding warfarin alone, it does not appear to be associated with any clinically important benefit or disadvantage for hospitalized non-critical care patients with INR between 4.5 and 8.9. Regardless of vitamin $\mathrm{K}$ dose or route, the outcomes examined-length of stay, incidence of warfarin resistance, incidence and duration of bridging anticoagulation, and risks of bleeding, thromboembolism, and death — were similar among patients who did and did not receive vitamin $\mathrm{K}$. The lack of evidence of benefit for clinically important outcomes with vitamin $\mathrm{K}$ suggests that the common practice of administering vitamin $\mathrm{K}$ to this population at the study centre requires re-evaluation.

These results are consistent with those of previous studies, which were conducted primarily in the outpatient setting., ${ }^{414-17}$ The largest published study was a multicentre randomized placebo-controlled trial by Crowther and others, ${ }^{4}$ who examined the use of oral vitamin K $1.25 \mathrm{mg}$ in outpatients for reversal of supratherapeutic INRs (4.5-10.0) without evidence of bleeding. Similar to our results, Crowther and others found that the change in INR 1 day after low-dose oral vitamin $\mathrm{K}$ administration was significantly greater in patients who received vitamin $\mathrm{K}$ than in those who did not $(p<0.001)$, but there were no differences in rates of bleeding, thromboembolism, or mortality at days 30 and 90. ${ }^{4}$ A smaller randomized placebo-controlled trial in the outpatient setting, which compared oral vitamin K $2.5 \mathrm{mg}$ and withholding warfarin alone, reported that vitamin $\mathrm{K}$ was associated with decreased time to reach INR below 4.0 (2.6 days versus 1.4 days, $p=0.006$ ), with no significant differences in incidence of thromboembolism, bleeding, or death. ${ }^{17}$ However, INR was below 2.0 for a significantly larger number of patientdays in the vitamin $\mathrm{K}$ arm. ${ }^{17} \mathrm{As}$ a result, the authors recommended against vitamin $\mathrm{K}$ administration in patients with low risk of bleeding. ${ }^{17}$

The current data also suggest that different doses and routes of vitamin $\mathrm{K}$ have similar efficacy and safety. These findings differ from those in a retrospective chart review by Tsu and others, ${ }^{8}$ who concluded that IV administration of vitamin $\mathrm{K}$ was associated with a more rapid decrease in INR than oral administration in a population of hospitalized patients. However, the patients who received oral vitamin $\mathrm{K}$ had higher mean baseline INR than those who received IV vitamin K (5.67 versus 5.09), and the mean decreases in INR at $24 \mathrm{~h}$ after the intervention were similar for the IV and oral routes (3.55 and 3.53, respectively). ${ }^{8}$ Consistent with our results, the incidence and duration of bridging anticoagulation, rate of thromboembolism, and 30-day mortality rate were not significantly different between the IV and oral administration groups. ${ }^{8}$ However, for reasons that the authors stated were unclear to them, hospital length of stay was significantly longer among patients who received vitamin $\mathrm{K}$ by the IV route than among those who received vitamin $\mathrm{K}$ by the oral route (13.54 versus 10.16 days, $p=0.02){ }^{8}$

The current study had several limitations. First, because of its small sample size, it was likely underpowered to detect differences in certain outcomes, such as major bleeding, thromboembolism, warfarin resistance, and death. This limitation may have also contributed to the lack of observed difference in length of stay between IV and oral vitamin $\mathrm{K}$, a result that conflicted with the data of Tsu and others (233 patients received IV vitamin $\mathrm{K}$ in the study by Tsu and others, ${ }^{8}$ as compared with 9 patients in the current study). A minor limitation during this study was that the highest quantifiable INR at the study hospital is 8.9. As such, it was not possible to quantify INR values of 9.0 or above. Given that the ACCP 2012 guidelines 5 recommend against vitamin K administration for patients with supratherapeutic INR less than 10.0 without evidence of bleeding, being able to identify patients with INR between 9.0 and 10.0 would have been valuable for this study. Finally, the study was limited by its nonrandomized, retrospective design. Lack of randomization predisposes the study results to selection bias, and reduces comparability among the groups analyzed. Important information that might have been missed through the retrospective analysis include preadmission medications that could interact with warfarin, compliance with the home warfarin regimen, and undocumented events and comorbidities (e.g., bleeding, thrombosis, severe liver disease). Furthermore, it was not possible to control for confounders with potential to affect INR (e.g., dietary vitamin K intake, administration of medications that interact with warfarin) or to follow patient outcomes beyond the discharge date.

\section{CONCLUSION}

In the study hospital, non-critical care patients with INR between 4.5 and 8.9 and no evidence of bleeding often receive vitamin K, contrary to the ACCP's 2012 guideline recommendations. Vitamin K administration was associated with a greater and more rapid decrease in INR but was not associated with any differences in patient-important clinical outcomes. This study was limited by its small sample size and retrospective design; larger prospective studies will be required to validate these results and provide further guidance for vitamin $\mathrm{K}$ prescribing practices in the acute care setting.

\section{References}

1. Kuruvilla M, Gurk-Turner C. A review of warfarin dosing and monitoring. Proc Bayl Univ Med Cent. 2001;14(3):305-6.

2. Hirsh J, Fuster V, Ansell J, Halperin JL. American Heart Association/ American College of Cardiology Foundation guide to warfarin therapy. J Am Coll Cardiol. 2003;41(9):1633-52.

3. Palareti G, Leali N, Coccheri S, Poggi M, Manotti C, D’Angelo A, et al. Bleeding complications of oral anticoagulant treatment: an inception-cohort, prospective collaborative study (ISCOAT). Lancet. 1996;348(9025):423-8.

4. Crowther MA, Ageno W, Garcia D, Wang L, Witt DM, Clark NP, et al. Oral vitamin $\mathrm{K}$ versus placebo to correct excessive anticoagulation in patients receiving warfarin: a randomized trial. Ann Intern Med. 2009;150(5): 293-300.

5. Holbrook A, Schulman S, Witt DM, Vandvik PO, Fish J, Kovacs MJ, et al. Evidence-based management of anticoagulant therapy: antithrombotic therapy and prevention of thrombosis, 9th ed: American College of Chest Physicians evidence-based clinical practice guidelines. Chest. 2012;141(2 Suppl): e152S-e184S. 
This single copy is for your personal, non-commercial use only.

For permission to reprint multiple copies or to order presentation-ready copies for distribution, contact CJHP at cjhpedit@cshp.ca

6. Ansell J, Hirsh J, Hylek E, Jacobson A, Crowther M, Palareti G. Pharmacology and management of the vitamin K antagonists: American College of Chest Physicians evidence-based clinical practice guidelines (8th edition). Chest. 2008;133(6 Suppl):160S-198S.

7. Whitling AM, Bussey HI, Lyons RM. Comparing different routes and doses of phytonadione for reversing excessive anticoagulation. Arch Intern Med. 1998;158(19):2136-40.

8. Tsu LV, Dienes JE, Dager WE. Vitamin $\mathrm{K}$ dosing to reverse warfarin based on INR, route of administration, and home warfarin dose in the acute/critical care setting. Ann Pharmacother. 2012;46(12):1617-26.

9. Levi M, Opal SM. Coagulation abnormalities in critically ill patients. Crit Care. 2006;10(4):222.

10. Heit JA, Melton LJ 3rd, Lohse CM, Petterson TM, Silverstein MD, Mohr $\mathrm{DN}$, et al. Incidence of venous thromboembolism in hospitalized patients vs community residents. Mayo Clin Proc. 2001;76(11):1102-10.

11. Classen DC, Jaser L, Budnitz DS. Adverse drug events among hospitalized Medicare patients: epidemiology and national estimates from a new approach to surveillance. Jt Comm J Qual Patient Saf. 2010;36(1):12-21.

12. Kotowycz MA, Filion KB, Joza J, Dube D, Reynolds MR, Pilote L, et al. In-hospital management of atrial fibrillation: the $\mathrm{CHADS}_{2}$ score predicts increased cost. Can J Cardiol. 2011;27(4):506-13.

13. Schulman S, Kearon C; International Society on Thrombosis and Haemostasis, Scientific and Standardization Committee, Subcommittee on Control of Anticoagulation. Definition of major bleeding in clinical investigations of antihemostatic medicinal products in non-surgical patients. J Thromb Haemost. 2005;3(4):692-4.

14. Ageno W, Crowther M, Steidl L, Ultori C, Mera V, Dentali F, et al. Low dose oral vitamin $\mathrm{K}$ to reverse acenocoumarol-induced coagulopathy: a randomized controlled trial. Thromb Haemost. 2002;88(1):48-51.

15. Ageno W, Garcia D, Silingardi M, Galli M, Crowther M. A randomized trial comparing $1 \mathrm{mg}$ of oral vitamin $\mathrm{K}$ with no treatment in the management of warfarin-associated coagulopathy in patients with mechanical heart valves. J Am Coll Cardiol. 2005;46(4):732-3.

16. Crowther MA, Julian J, McCarty D, Douketis J, Kovacs M, Biagoni L, et al. Treatment of warfarin-associated coagulopathy with oral vitamin K: a randomised controlled trial. Lancet. 2000;356(9241):1551-3.
17. Patel RJ, Witt DM, Saseen JJ, Tillman DJ, Wilkinson DS. Randomized, placebo-controlled trial of oral phytonadione for excessive anticoagulation. Pharmacother J Hum Pharmacol Drug Ther. 2000;20(10):1159-66.

Claire Tai, BSc(Pharm), ACPR, is a Clinical Pharmacist with Fraser Health, Surrey, British Columbia.

Hilary Wu, BSC(Pharm), ACPR, PharmD, is a Clinical Pharmacist with Providence Health Care, Vancouver, British Columbia.

Cindy San, BSc(Pharm), ACPR, PharmD, is a Clinical Pharmacy Specialist in Emergency Medicine with St Paul's Hospital, Providence Health Care, Vancouver, British Columbia

Doson Chua, BSC(Pharm), PharmD, BCPS (AQ), is a Clinical Pharmacy Specialist in Cardiology with St Paul's Hospital, Providence Health Care, and a Clinical Professor with the Faculty of Pharmaceutical Sciences, The University of British Columbia, Vancouver, British Columbia.

Competing interests: None declared.

\section{Address correspondence to:}

Claire Tai

Pharmacy Department

Surrey Memorial Hospital

1375096 Avenue

Surrey BC V3V $1 Z 2$

e-mail: claire.tai@fraserhealth.ca

Funding: Funding to obtain patient data from the hospital laboratory department was supported by the Pharmacy Department at St Paul's Hospital. No other financial support was provided for this work.

Acknowledgement: The authors thank Jennifer Ho for her assistance in the collection of data for this study. 